8

cambridge.org/enc

\section{Research Paper}

Cite this article: Koskimäki T et al. (2021) Impact of individual protected areas on deforestation and carbon emissions in Acre, Brazil. Environmental Conservation 48: 217-224. doi: 10.1017/S0376892921000229

\section{Received: 30 October 2020}

Revised: 3 June 2021

Accepted: 4 June 2021

First published online: 1 July 2021

\section{Keywords:}

arc of deforestation; counterfactual; deforestation front; effectiveness; REDD+; tropics

\section{Author for correspondence:}

Teemu Koskimäki,

Email: teemu.koskimaki@anu.edu.au

\title{
Impact of individual protected areas on deforestation and carbon emissions in Acre, Brazil
}

\author{
Teemu Koskimäki $^{1,2}$ (1) J Johanna Eklund $^{3}$ (1) , Gabriel M Moulatlet ${ }^{1,4}$ (1) and \\ Hanna Tuomisto ${ }^{1}$ (D) \\ ${ }^{1}$ Department of Biology, University of Turku, 20014 Turun yliopisto, Finland; ${ }^{2}$ Crawford School of Public Policy, \\ Australian National University, ACT 2601, Australia; ${ }^{3}$ Department of Geosciences and Geography, University of \\ Helsinki, PL 64 Gustaf Hällströmin katu 2, 00014 University of Helsinki, Finland and ${ }^{4}$ Facultad de Ciencias de la \\ Tierra y Agua, Universidad Regional Amazónica Ikiam, km 7 vía a Muyuna, Tena, Napo, Ecuador
}

\begin{abstract}
Summary
Protecting tropical forests from deforestation is important for mitigating both biodiversity loss and anthropogenic climate change. In Amazonia, a common approach to protected area (PA) impact studies has been to investigate differences among broad PA categories, such as strictly protected, sustainable use and indigenous areas, yet these may be insufficient for the management of PAs at local scales. We used a matching method to compare impacts and carbon emissions avoided during 2011-2016 of individual PAs in the state of Acre (Brazil). Although most PAs had a positive impact and effectively prevented forest loss, we observed substantial variation among them in terms of impacts, pressures and emissions during our study period. The impacts varied from 3.6\% avoided to $15.6 \%$ induced forest loss compared to expected levels of deforestation estimated for each PA using the matching method. All but a few PAs helped avoid substantial amounts of emissions. Our results emphasize the need for more PA impact studies that compare multiple PAs at the individual level in Amazonia and beyond.
\end{abstract}

\section{Introduction}

Most forest conversion to other land uses takes place in the tropical domain where intact forests still exist, particularly Central and South America, sub-Saharan Africa and South and SouthEast Asia (MacDicken et al. 2015, FAO 2016). These remaining forests not only harbour the majority of terrestrial species (FAO 2016), but they are also an important reservoir of sequestered carbon (Saatchi et al. 2011) and provider of indispensable provisioning, regulating, supporting and cultural ecosystem services for humanity (IPBES 2019). Hence, protecting tropical forests is important for mitigating both biodiversity loss and anthropogenic climate change, with several co-benefits (Goetz et al. 2015, Nogueira et al. 2018).

The future of tropical forests remains uncertain due to manifold incentives to convert them to other land uses, particularly through the expansion of transport infrastructure, settlements, markets, cattle ranching and cultivation (Geist \& Lambin 2002, Araújo et al. 2017, Nogueira et al. 2018). In the Brazilian Amazonia, the rate of deforestation increased after 2012 (INPE 2018 , 2021), when the country altered its Forest Code, which regulates land use and the management of private properties (Federal Law 12.727; see Soares-Filho et al. 2014). Since then, the rate of deforestation has continued to increase in Brazil, fed by economic recessions and political changes (Watts 2016, BBC 2017, Escobar 2019, Menton et al. 2021).

The rising rates of deforestation increase the importance of existing protected areas (PAs) in Brazil, which in turn heightens the relevance of knowing how well PAs prevent deforestation (Ferreira et al 2005, Veríssimo et al. 2011, Cabral et al. 2018). Not all PAs are equal, and their specific spatial and environmental contexts, such as the agricultural suitability of the land or the accessibility of the forests, need to be considered when their effectiveness in preventing forest loss (hereafter referred to as 'impact'; use of terminology according to Pressey et al. 2015) is evaluated (Joppa \& Pfaff 2011, Nolte et al. 2013, Eklund et al. 2016). This can be done through the use of matching methods, which estimate PA impact while accounting for effects of confounding landscape variables (Andam et al. 2008, Gaveau et al. 2009). These methods compare the fraction of forested area lost within a PA to the fraction lost in similar non-PAs (the expected deforestation 'pressure'), and the resulting impact estimates reflect how the existence of the PA, and not the confounding landscape variables, has helped to retain forest cover.

Until recently, PA impact studies have primarily focused either on the overall average impact of protection at national to global scales (Joppa \& Pfaff 2011, Heino et al. 2015) or on the comparative impact of broad PA categories (e.g., Soares-Filho et al. 2010, Nolte et al. 2013, Pfaff et al. 
2014, Schleicher et al. 2017). For research comparing the impact of multiple PAs in the Brazilian Amazonia, the norm has so far been comparisons of aggregated impacts and pressures between broad PA categories, specifically strictly protected, sustainable use and indigenous areas, among which significant differences have generally been found (e.g., Soares-Filho et al. 2010, Nolte et al. 2013, Pfaff et al. 2014, Schleicher et al. 2017).

However, recent studies from China (Zhao et al. 2019), Indonesia (Shah \& Baylis 2015) and Eastern Europe (Butsic et al. 2017) have demonstrated that considerable heterogeneity exists within broad protection categories; the broad generalizations may even be misleading for conservation decisions at the local scale (Shah \& Baylis 2015, Butsic et al. 2017). There is a distinct need to complement such generalized findings in the Brazilian Amazonia by estimating and comparing the impacts of multiple individual PAs, thus providing comparative individual-level impact estimates (Zhao et al. 2019).

Addressing this gap is the focus of this paper. In the state of Acre, we ask whether the heterogeneity observed in other parts of the world can be observed in the Brazilian Amazonia. Specifically, we ask whether the impacts (avoided deforestation) and pressures (level of deforestation expected in the absence of protection) differ significantly from each other between broad protection categories and compare this to the variation at the level of individual PAs. In addition, we also ask about the quantity of carbon emissions each PA avoided during the study period. Our hypothesis is that there will be differences between broad protection categories, but we also expect to find substantial and important variation between individual PAs within each category.

\section{Methods}

\section{Study area}

The state of Acre is situated in the westernmost part of the Brazilian Amazonia, and it has established an extensive PA network to protect its highly biodiverse forests (Fig. 1) (Jenkins et al. 2015). Approximately $46 \%\left(75497 \mathrm{~km}^{2}\right)$ of Acre is dedicated to PAs (Government of Acre 2017; see Section 1 in Appendix S1 (available online) for more details of the study area).

\section{Data}

To enable comparisons with earlier studies, we followed the common approach of grouping PAs into three broad categories: (1) strictly PAs, which include state and national biological stations, national and state parks, ecological stations and biological reserves; (2) sustainable use areas, which include state and national forests, extractive reserves and sustainable development reserves; and (3) indigenous areas (for details, see Nolte et al. 2013). The remaining areas (two Environmental Protection Areas and two Areas of Relevant Ecological Interest), which had been excluded in earlier studies, were categorized as 'other' to determine whether the remaining areas differed from the rest when grouped.

We excluded small overlaps between PAs that seemed to represent inaccuracies in the mapped polygon borders. However, some overlapping areas were so large that they likely correspond to cases where an area was protected under two management categories. We combined the largest overlapping areas ( $>20 \mathrm{~km}^{2}$ in size, to enable sufficient sampling) into a group of their own, referred to as 'overlapping protection' or simply 'overlap', to account for their contribution in the analyses.
To avoid sampling areas that did not have forests at the start of the study period, we defined forested areas based on forest cover values in the 2010 Vegetation Continuous Fields (VCF) collection, which indicated the percentage of forest cover at 250-m resolution for the year 2010 (DiMiceli et al. 2011). We defined pixels with 45\% forest cover as forest and pixels below this threshold as non-forest. We obtained a deforestation dataset spanning the years from 2011 to 2016 by combining annual PRODES deforestation polygons (INPE 2017).

Following earlier studies (Joppa \& Pfaff 2011, Nolte et al. 2013, Eklund et al. 2016), we used covariates to ensure that comparisons were made between environmentally similar areas (Table 1 \& Section 2.2 in Appendix S1), controlling for potential confounding factors such as travel time (i.e., access) to regional markets (utilizing code provided by Weiss et al. 2018) and agricultural suitability of the land (Laurance et al. 2002). The travel time calculation considered the distances to roads, rivers and major cities (over 10000 people), among other relevant considerations (for details, see Appendix S1). The spatial analyses were performed with QGIS (v3.2.3-Bonn) and the travel times were calculated in $R$ (R Studio, version 1.1.453).

\section{Matching}

We used a matching method (Eklund et al. 2016) to compare individual PAs to environmentally similar non-PAs. To get the datasets needed for matching, we took random samples of points from within the forested areas of each PA and from within the forested areas of the non-PA of Acre, equal to $10 \%$ of the forested pixels in each area. Sampling of each PA and the non-PAs was repeated 10 times to control for potential effects of the random sample on our results and to gain a measure of uncertainty. We ran the matching process separately for each of the 10 repeats and aggregated the resulting 10 impact estimates for each PA. The total number of sample points over all repeats for all PAs was 2739400 points, counting both protected and non-protected points (see Section 2.3 in Appendix S1 for details). For additional details and a visualization of the approach, see Flowchart S1, Appendix S1, and Eklund et al. (2016). We used the $R$ package $s p$ (Pebesma \& Bivand 2005) for the random sampling. We performed the matching process using Taito supercluster, which enabled parallel computation with 256 cores (computational resources available for research from CSC - IT Center for Science, Finland).

\section{Avoided deforestation and carbon emissions}

Using the impact estimates and the number of forested pixels in each PA, we calculated estimates of avoided deforestation in hectares. The $95 \%$ confidence intervals of the impact estimates were used to calculate the confidence range for the hectare estimates. Following this, we calculated a mean carbon density per hectare for each PA using a biomass layer obtained from Rödig et al. (2017) with the assumption that the carbon content of the biomass is $47.1 \%$ (the observed mean carbon fraction for tropical angiosperms; Thomas \& Martin 2012).

We calculated the avoided $\mathrm{CO}_{2}$ emissions for each PA by multiplying the carbon density of each PA by the estimated area of forest loss that each PA had avoided and then multiplying the result by 0.9 , which we assumed to be the fraction of biomass converted into $\mathrm{CO}_{2}$ following deforestation (Houghton et al. 2000, Numata et al. 2011). We used the coefficient of variation for the biomass estimates provided by Rödig et al. (2017) together with the lower and upper $95 \%$ confidence interval values of the estimated hectares 


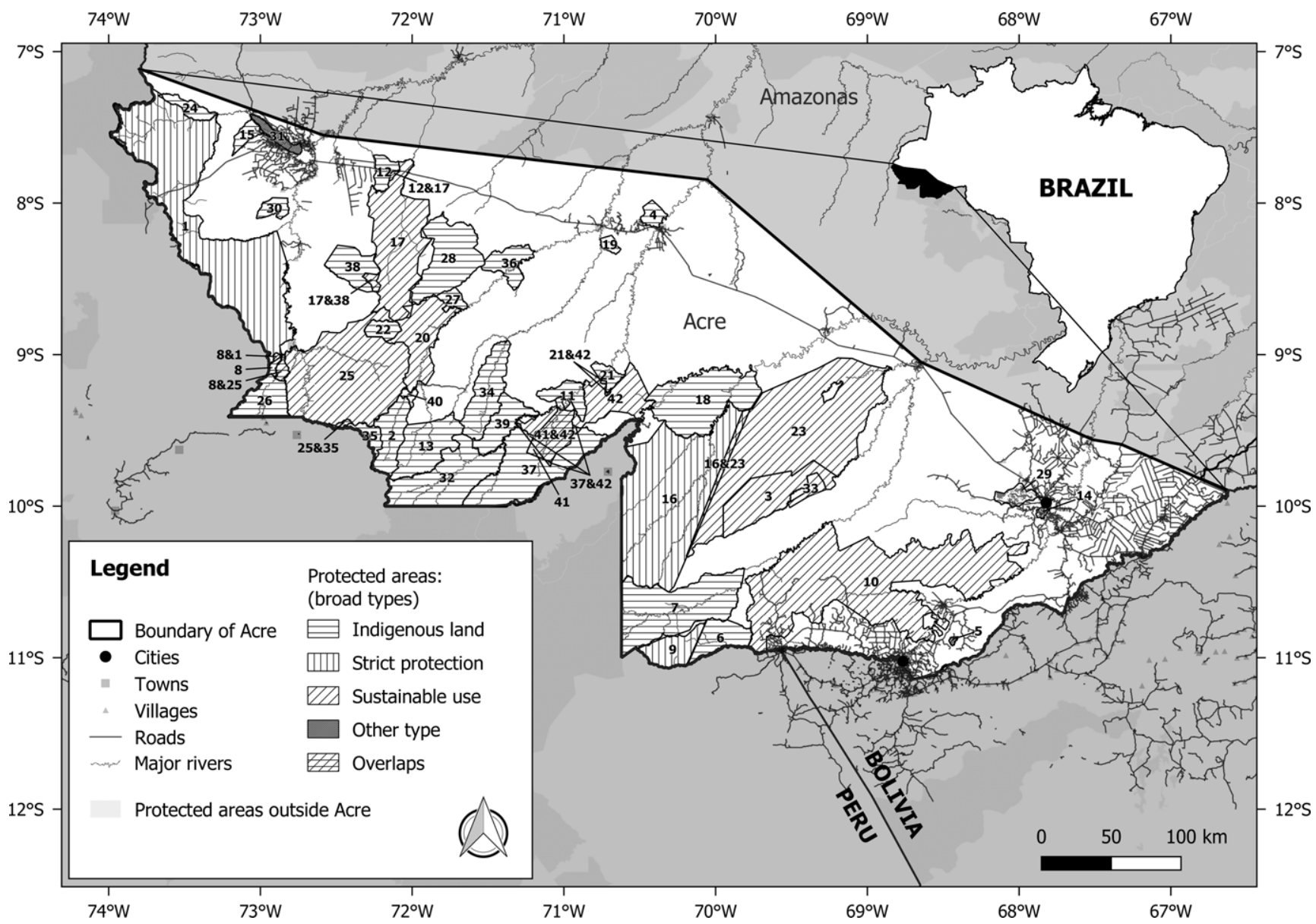

Fig. 1. Protected areas (PAs) in the state of Acre, Brazil. The areas with overlapping protection were analysed independently and have an ampersand in between the PA numbers. See Table S1 for PA names and additional information.

of avoided deforestation to calculate low and high estimates for the avoided carbon emissions (for more details of the emissions calculations, see Section 2.6 in Appendix S1).

\section{Results}

Overall, a comparison of forest loss within all PAs and their matched areas indicated that there was less deforestation per unit area within Acre's PAs than in the non-protected control areas (Wilcoxon signed rank test, $\mathrm{V}=55, \mathrm{p}<0.001$ ). The average PA impact, calculated across all PAs and overlaps, was $0.4 \%$ (standard deviation 2.4).

The broad PA categories did not differ from each other significantly in their impact estimates (Kruskal-Wallis rank sum test, $\left.\chi^{2}=0.54, \mathrm{df}=4, \mathrm{p}=0.97\right)$. Although most individual PAs had a positive impact in terms of avoiding deforestation (Fig. 2 \& Table S2), there was substantial variation among them. The impact estimates for individual PAs ranged from avoided deforestation of $3.6 \%$ of the forested area (PA 14, Environmental Protection Area in category 'other') to induced deforestation of $15.6 \%$ of the forested area (PA 5, Area of Relevant Ecological Interest in category 'other'), compared to the levels of deforestation expected via matching (Fig. 2 \& Table S2). The results for the indigenous areas varied from $-0.1 \%$ induced to $3.0 \%$ avoided deforestation, with an overall average of $0.6 \%$ avoided deforestation (Figs $2 \&$ S1 \& Table S1). Out of all PAs, two had a negative impact, which means that deforestation was estimated to have been induced rather than avoided as a result of their protection status (PAs 5 and 22; Fig. 2). Of the nine overlaps we included, in all but one case the overlaps were between an indigenous area and a PA in another category. Substantial variation and no clear patterns existed in the overlap category.

Although all PAs faced deforestation pressures, there was great variation among individual PAs in terms of the amount of pressure (Fig. S2 \& Table S2). Seven PAs and two areas with overlapping protection were situated in areas with negative confounding effects, which means that the covariates indicated that they confronted a higher than average pressure to be deforested. The seven PAs were ARIE Seringal Nova Esperança (PA 5), APA Igarapé São Francisco (PA 29), APA Lago do Amapá (PA 14), INDIG Cabeceira do Rio Acre (PA 6), RESEX Chico Mendes (PA 10), INDIG Arara do Rio Amônia (PA 8) and ARIE Japiim-Pentecoste (PA 31), ordered from highest to lowest threat.

In terms of deforestation pressure, the estimates for the broad PA categories did not differ from each other significantly (Kruskal-Wallis rank sum test, $\chi^{2}=0.45, \mathrm{df}=2, \mathrm{p}=0.80$ ). However, PAs in the category 'other' faced higher pressures than the other three categories (Fig. S2 \& Table S2). Pressures were particularly high for PAs 14 and 29, the two Environmental Protection Areas (APA), and for PA 5, which is an Area of Relevant Ecological Interest (ARIE) (Fig. S2 \& Table S2). 
Table 1. Datasets used in this study. Resolutions are rounded.

\begin{tabular}{|c|c|c|c|}
\hline Variable & Description & Resolution & Source \\
\hline Protected areas & Protected area polygons for Brazil & - & $\begin{array}{l}\text { UNEP-WCMC \& IUCN (2018), the World } \\
\text { Database on Protected Areas (WDPA) }\end{array}$ \\
\hline Deforestation & $\begin{array}{l}\text { PRODES dataset based on Landsat imagery. Years 2011-2016 } \\
\text { combined }\end{array}$ & $250 \mathrm{~m}$ & $\begin{array}{l}\text { Brazilian Institute for Space Research } \\
\text { (Instituto Nacional de Pesquisas } \\
\text { Espaciais; INPE 2017). }\end{array}$ \\
\hline Deforestation front & Polygons of the deforestation fronts in the Amazon & - & WWF (2015) \\
\hline Baseline forest cover & Percentage tree cover in 2010 . VCF dataset & $250 \mathrm{~m}$ & $\begin{array}{l}\text { Global Land Cover Facility, University of } \\
\text { Maryland (DiMiceli et al. 2011) }\end{array}$ \\
\hline \multicolumn{4}{|l|}{ Covariates } \\
\hline Elevation & SRTM 90 m Digital Elevation Data & $90 \mathrm{~m}$ & Jarvis et al. (2008) \\
\hline Slope & Calculated from the elevation data & $90 \mathrm{~m}$ & - \\
\hline Floodable areas & GlobCover dataset. Year 2009 & $300 \mathrm{~m}$ & $\begin{array}{l}\text { European Space Agency GlobCover Portal } \\
\text { (ESA, 2010). }\end{array}$ \\
\hline Precipitation & Annual precipitation data & $1 \mathrm{~km}$ & $\begin{array}{l}\text { CHELSA Bioclim Annual precipitation (Bio } \\
\text { 12) dataset (Karger et al. 2017) }\end{array}$ \\
\hline \multirow[t]{3}{*}{ Distance to forest edge } & \multirow{3}{*}{$\begin{array}{l}\text { Raster surface with shortest Euclidean distances to forest edge. } \\
\text { Calculated with the baseline forest cover (VCF), OSM roads and } \\
\text { OSM rivers layers }\end{array}$} & \multirow[t]{3}{*}{$250 \mathrm{~m}$} & Individual datasets from: \\
\hline & & & OSM products downloaded in February \\
\hline & & & $\begin{array}{l}2018 \text { with QuickOSM plugin in QGIS. VCF } \\
\text { as above }\end{array}$ \\
\hline Travel time/accessibility & $\begin{array}{l}\text { Raster surface with fastest travel times to urban areas with }>10 \\
000 \text { people. Calculated with the latest available data }\end{array}$ & $1 \mathrm{~km}$ & $\begin{array}{l}\text { Calculated using the approach and code } \\
\text { of Weiss et al. (2018) }\end{array}$ \\
\hline
\end{tabular}

OSM = OpenStreetMap; SRTM = Shuttle Radar Topography Mission; VCF = Vegetation Continuous Fields.

On the basis of the impact estimates, we calculated that the PAs of Acre avoided a total of c. 46600 ha (41 956-51 187 ha) of deforestation during the study period (Table S3), corresponding to 5800 kilotonnes (5024-6644 kilotonnes) of avoided carbon emissions (Fig. 3 \& Table S3). PAs 10 (1923 kilotonnes) and 1 (597 kilotonnes) avoided the most emissions on average. Great variation existed among PAs in each broad category, with larger PAs generally avoiding more emissions within each category (Fig. 3 \& Table S3).

\section{Discussion}

Our results for the state of Acre in Amazonia showed great heterogeneity at the level of individual PAs, which corroborated findings from other parts of the world (Shah \& Baylis 2015, Butsic et al. 2017, Zhao et al. 2019). Our results showed similar pressures and impacts for each broad PA category during our study period (2011-2016), contrary to what was expected on the basis of earlier studies (e.g., Soares-Filho et al. 2010, Nolte et al. 2013, Pfaff et al. 2014). The reason why PAs in the category 'other' faced substantially higher pressures than PAs in the other three broad categories can be explained by their location, as all PAs in the 'other' category are within the general deforestation front area (WWF 2015, Pacheco et al. 2021), and all except PA 5 are also located near major cities. Importantly, our results reveal that all but a few PAs had helped to avoid substantial amounts of emissions.

It is worth considering some of the limitations of our study. Our definition of forests as pixels with $45 \%$ or above forest cover in the VCF dataset and non-forests as pixels below this threshold was arbitrary. A different threshold may yield different results because when the threshold is lowered, the potential to omit existing forests, which may have experienced deforestation, declines. However, the trade-off is that simultaneously the risk of sampling non-forest areas that cannot experience deforestation grows (see Section 2.1 in Appendix S1). Future studies could look into alternative forest cover rasters and optimal thresholds for different geographical areas, particularly since the VCF data are not available annually.
We did not consider displacement of forest conversion (i.e., leakage). Out-to-out leakage, meaning deforestation performed by illegal land grabbers who have no attachment to place (Azevedo-Ramos et al. 2020), was not considered because matching cannot reliably detect it. In-to-out leakage, or spillover, was not considered either, because previous research has found little to no support for the phenomenon (Soares-Filho et al. 2010, Carranza et al. 2014, Lui \& Coomes 2016). In fact, PAs may sometimes reduce deforestation in their vicinity (Soares-Filho et al. 2010). If so, then our impact results may be considered somewhat conservative, and the potential reduction of deforestation near PAs may have contributed some additional emission reductions. Moreover, by preventing edge-related forest degradation that may occur with deforestation, the PAs may have prevented as much as $10 \%$ more carbon emissions than what we estimated, although this number remains uncertain (Numata et al. 2010, Nogueira et al. 2018). We also did not account for belowground biomass due to a lack of reliable data for high-biomass forests (Mokany et al. 2006). Our estimate will also be more conservative if the carbon content of biomass turns out to be higher than the estimate we used.

In addition, while the lack or presence of deforestation is a clear representation of PA impact, it should not be considered as the sole determinant of it; PAs can be effective along other dimensions as well. Forests may be degraded, for example, by selective logging or by unsustainable levels of hunting, which can result in an 'empty forest' (Redford 1992, Benítez-López et al. 2019). Decline in species diversity induced by hunting can have repercussions on the ecosystem functions and services that the forests provide, affecting both the composition of the forests and their carbon density (Lewis et al. 2015).

Given that evidence suggests an increasing rate of PA downgrading, downsizing and degazettement in Brazil (Bernard et al. 2014), we should avoid giving the impression that the type of PA does not matter at all, which could be falsely used to support PA downgrading. There are real differences between the various protection types in terms of how much human activity, in particular land-use change, is allowed within the PAs (Nolte et al. 2013). 


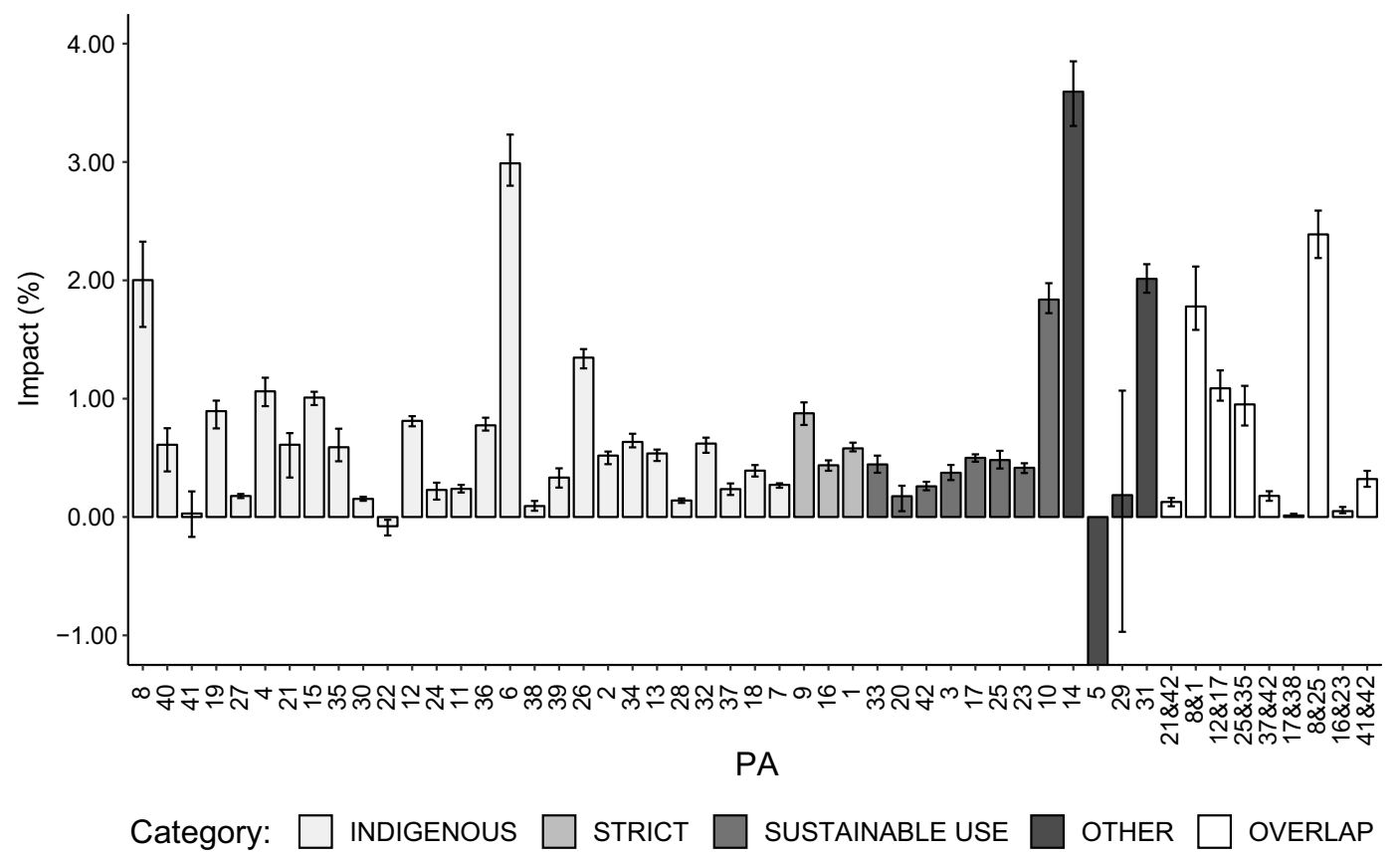

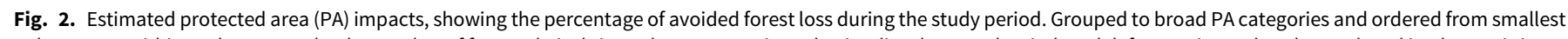

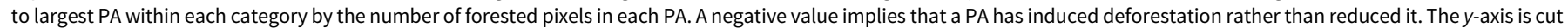
off as PA 5 extended to $-15.59 \%$ (confidence interval $-21.82 \%$ to $-12.43 \%$ ). 95\% confidence intervals derived with a bootstrap method (see Section 2.5 in Appendix S1).

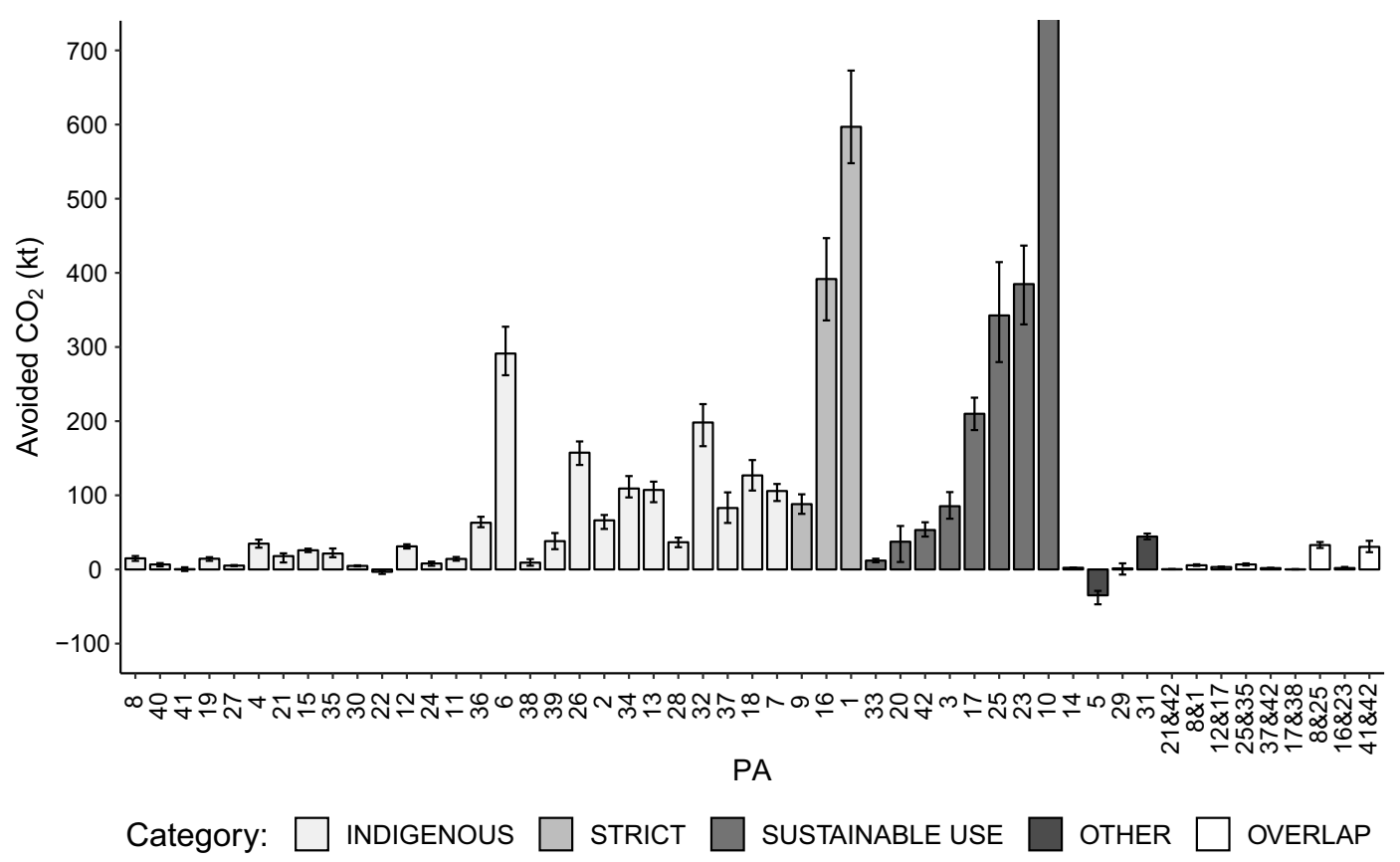

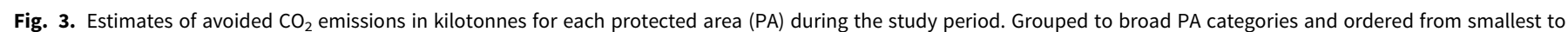

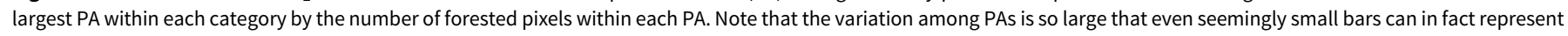

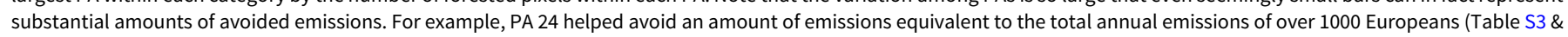

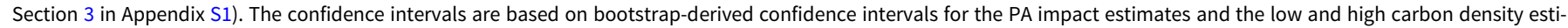
mates for each PA (see Sections 2.5 and 2.6 in Appendix S1). The $y$-axis is cut off as PA 10 extended to 1923.17 kilotonnes (confidence interval $1734.22-2147.03$ kilotonnes).

Even though our data did not show differences in impact between broad protection categories, such could still exist. Previous studies have reported differences in aggregated impacts and pressures for the broad categories in the entire Brazilian Amazonia (SoaresFilho et al. 2010, Nolte et al. 2013), the Brazilian Cerrado
(Carranza et al. 2014), the Peruvian Amazonia (Schleicher et al. 2017) and the state of Acre (Pfaff et al. 2014).

Pfaff et al. (2014) compared the broad PA categories in Acre and found that only sustainable use areas had a significant impact when compared to matched unprotected lands, in both 2000-2004 and 
2004-2008 (2.65\% and $1.71 \%$ of avoided forest loss, respectively). These authors concluded that 'clearing prevented by sustainable use areas is higher, since their locations feature higher threat'. The impact was lower for the latter period since deforestation pressures had also decreased (Pfaff et al. 2014).

Our results differ from the results of Pfaff et al. (2014) in three key respects. Firstly, we found all broad PA categories to have significantly positive impacts as well as pressures. Secondly, we found that the broad PA categories did not differ from each other because the pressures were uniform. During our study period (2011-2016), the amount of deforestation in Acre was lower, on average, than during either one of the periods considered by Pfaff et al. (2014), although the deforestation rate in our study period was rising from year to year, instead of declining as in Pfaff et al.'s study periods (INPE 2021). It may be that as the more accessible areas have been gradually deforested, the deforestation pressures have become more uniform for each broad PA category in Acre. Thirdly, our results indicate that it is more important to consider and compare the impacts of individual PAs than broad PA categories, particularly at the state level, given the small number of PAs in each category and the huge potential for heterogeneity that exists among individual PAs within each category. This is especially true for reducing emissions from deforestation and forest degradation (REDD+).

The following case examples demonstrate how the impact estimate of a PA is always dependent on the spatiotemporal context. According to our results, deforestation was induced in two PAs during our study period, rather than being reduced. PA 5 (Seringal Nova Esperança, an Area of Relevant Ecological Interest) had the largest negative confounding effect out of all PAs, indicating high pressure, and the PA experienced a very high fraction of deforestation, equivalent to $15.6 \%$ of its forested area. Previous research has explained how shortcomings in management, together with a lack of recognition by the inhabitants, has produced socio-environmental conflicts and negative outcomes for the forests within the PA (Lemos Abreu 2015). Although a large portion of the area has now been lost, the remaining forests might still be highly valuable ecologically, and thus resolving the socioenvironmental conflicts should receive immediate attention from all relevant stakeholders. PA 22 (indigenous territory of the Jaminawa and Arara of the Bagé river) also seemed to have induced deforestation, even though the confounding effect for PA 22 indicated lower than average pressures. This can be explained by the fact that PA 22 is a relatively remote and small indigenous area with low expected deforestation, and therefore even the 22.47 ha of deforestation that seems to have been induced (Table S3) was enough to result in a slightly negative impact estimate.

Examples of PAs that had high impact estimates include PAs 14 and 10. PA 14 is the small Lago do Amapá Environmental Protection Area near Acre's capital city, Rio Branco, and it was estimated to have prevented $c .36$ ha of deforestation (equivalent to $3.6 \%$ of its forested area). However, PA 14 cannot be considered as particularly 'successful', given the amount of deforestation it has experienced over the years, with practically no visible difference to surrounding areas. Similarly, PA 10, the Chico Mendes Extractive Reserve, had a much higher impact than other sustainable use areas at $1.8 \%$, but the impact estimate does not tell the whole story due to the high pressures in the surrounding areas. PA 10 also experienced the largest losses of forest cover and carbon, in absolute terms, out of all considered PAs due to a combination of impact level, size and pressures. The large negative confounding effects for PAs 14 and 10 (Fig. S2 \& Table S2) indicate that both were under high pressures, which tested their impactfulness, allowing for high estimated impacts. This demonstrates how impact does not necessarily equate to success and a lack of threat.

Addressing the specific reasons why some PAs do well while others do not and examining what could explain the variation in impacts within protection categories are beyond the scope of this paper, but our findings present pertinent opportunities for future research. As our results demonstrate, remote sensing research can be used to identify potential study subjects for on-the-ground research at the local level to clarify what are the ingredients of a successful PA.

When interpreting the findings for indigenous lands, it is good to remember that these lands were established for the people, not the forests, yet forests are clearly protected by them. Our results showed that $81 \%$ of the indigenous areas experienced some deforestation during the study period (range $0.01-0.28 \%$ of forested area) compared with $67 \%$ of the strict and sustainable use categories combined (range $0.01-20.74 \%$ of forested area). The variation in impact we found between indigenous areas was also noted by Nolte et al. (2013), who found indigenous lands to be the most effective category in high-pressure locations in Brazil, and we concur with their reasoning that deforestation in indigenous areas may be driven more by internal processes than by external pressures. Future studies could investigate the reasons why deforestation rates are generally lower but more common in indigenous areas than in other broad PA categories and whether there are qualitative differences in the pressures and their long-term outcomes.

As with impacts and pressures, our results showed great variation for avoided carbon emissions, which were nonetheless clearly influenced by the size of the PA within all broad protection categories. This is because even a small percentage of avoided forest loss can mean substantial differences in terms of hectares and avoided carbon emissions when the total area of the PA is large. The larger the forest, the more emissions it can help avoid. This is why PAs 10 and 1 - the two largest in size - also avoided the most emissions.

\section{Conclusions}

Our analyses emphasize the importance of focusing on the variability at the level of individual PAs so as not to discount the heterogeneity, complexity and context specificity of conservation. When impact estimates at the level of individual PAs are available and can be compared, resource use and management practices can be optimized to achieve conservation goals (Shah \& Baylis 2015, Butsic et al. 2017, Zhao et al. 2019). Our results emphasize the importance of comparative individual-level impact estimates for PAs to help guide the conservation of tropical forests for Amazonia and for the other deforestation front areas around the globe.

Acknowledgements. We would like to thank three anonymous reviewers whose feedback greatly benefitted this paper. Daniel J Weiss provided helpful information on the travel time calculations. We also acknowledge CSC - IT Center for Science, Finland, for computational resources. TK wishes to thank Henna E Virtanen for her helpful comments, encouragement and abiding love and support throughout this work.

Financial support. Our work was supported by the Kone foundation (grant 201608614 to JE) and the University of Turku Graduate School (grant to GMM).

\section{Conflict of interest. None.}

Ethical standards. None. 
Supplementary material. To view supplementary material for this article, please visit https://doi.org/10.1017/S0376892921000229.

\section{References}

Andam KS, Ferraro PJ, Pfaff A, Sanchez-Azofeifa GA, Robalino JA (2008) Measuring the effectiveness of protected area networks in reducing deforestation. Proceedings of the National Academy of Sciences of the United States of America 105: 16089-16094.

Araújo E, Barreto P, Baima S, Gomes M (2017) Unidades de Conservação mais desmatadas da Amazônia Legal (2012-2015). Belém, Brazil: Imazon.

Azevedo-Ramos C, Moutinho P, Arruda VL, Stabile MCC, Alencar A, Castro I, Ribeiro JP (2020) Lawless land in no man's land: the undesignated public forests in the Brazilian Amazon. Land Use Policy 99: 104863.

BBC (2017) Brazil emerges from recession as GDP grows 1\% [www document]. URL http://www.bbc.com/news/world-latin-america-40120364

Benítez-López A, Santini L, Schipper AM, Busana M, Huijbregts MAJ (2019) Intact but empty forests? Patterns of hunting induced mammal defaunation in the tropics. PLoS Biology 17: e3000247.

Bernard E, Penna LAO, Araújo E (2014) Downgrading, downsizing, degazettement, and reclassification of protected areas in Brazil. Conservation Biology 28: 939-950.

Butsic V, Munteanu C, Griffiths P, Knorn J, Radeloff VC, Lieskovský J et al. (2017) The effect of protected areas on forest disturbance in the Carpathian Mountains 1985-2010. Conservation Biology 31: 570-580.

Cabral AIR, Saito C, Pereira H, Laques AE (2018) Deforestation pattern dynamics in protected areas of the Brazilian Legal Amazon using remote sensing data. Applied Geography 100: 101-115.

Carranza T, Balmford A, Kapos V, Manica A (2014) Protected area effectiveness in reducing conversion in a rapidly vanishing ecosystem: the Brazilian Cerrado. Conservation Letters 7: 216-223.

DiMiceli CM, Carroll ML, Sohlberg RA, Huang C, Hansen MC, Townshend JRG (2011) Annual Global Automated MODIS Vegetation Continuous Fields (MOD44B) at $250 \mathrm{~m}$ Spatial Resolution for Data Year 2010, Collection 5, Percent Tree Cover. College Park, MD, USA: University of Maryland.

Eklund J, Blanchet FG, Nyman J, Rocha R, Virtanen T, Cabeza M (2016) Contrasting spatial and temporal trends of protected area effectiveness in mitigating deforestation in Madagascar. Biological Conservation 203: 290-297.

ESA (2010) GlobCover 2009, Global Land Cover Map V2.3 [www document]. URL http://due.esrin.esa.int/page_globcover.php

Escobar H (2019) Science and politics: Bolsonaro's first moves have Brazilian scientists worried. Science 363: 330.

FAO (2016) State of the World's Forests 2016. Forests and Agriculture: Land-Use Challenges and Opportunities. Rome, Italy: FAO.

Ferreira, LV, Venticinque, E, Almeida, S (2005). O desmatamento na Amazônia e a importância das áreas protegidas. Estudos avançados 19: $157-166$.

Gaveau DLA, Epting J, Lyne O, Linkie M, Kumara I, Kanninen M, LeaderWilliams N (2009) Evaluating whether protected areas reduce tropical deforestation in Sumatra. Journal of Biogeography 36: 2165-2175.

Geist HJ, Lambin EF (2002) Proximate causes and underlying driving forces of tropical deforestation. BioScience 52: 143-150.

Goetz SJ, Hansen M, Houghton RA, Walker W, Laporte N, Busch J (2015) Measurement and monitoring needs, capabilities and potential for addressing reduced emissions from deforestation and forest degradation under REDD. Environmental Research Letters 10: 123001.

Government of Acre (2017) Acre em Números 2017. Acre, Brazil: Government of Acre.

Heino M, Kummu M, Makkonen M, Mulligan M, Verburg PH, Jalava M, Räsänen TA (2015) Forest loss in protected areas and intact forest landscapes: a global analysis. PLoS ONE 10: e0138918.

Houghton RA, Skole DL, Nobre CA, Hackler JL, Lawrence KT, Chomentowski WH (2000) Annual fluxes of carbon from deforestation and regrowth in the Brazilian Amazon. Nature 403: 301-304.

INPE (2017) PRODES [www document]. URL http://terrabrasilis.dpi.inpe.br
INPE (2018) PRODES: Monitoramento da Floresta Amazônica Brasileira por Satélite [www document]. URL http://www.obt.inpe.br/prodes/

INPE (2021) TerraBrasilis [www document]. URL http://terrabrasilis.dpi.inpe. br/app/dashboard/deforestation/biomes/legal_amazon/rates

IPBES (2019) Global Assessment on Biodiversity and Ecosystem Services: Chapter 2.3. Status and Trends - Nature's Contributions to People (Unedited draft chapter 31 May 2019) [www document]. URL https:// www.ipbes.net/sites/default/files/ipbes_global_assessment_chapter_2_3_ncp_ unedited_31may.pdf

Jarvis A, Reuter HI, Nelson A, Guevara E (2008) Hole-filled SRTM for the globe Version 4, available from the CGIAR-CSI SRTM $90 \mathrm{~m}$ database [www document]. URL https://cgiarcsi.community

Jenkins CN, Alves MAS, Uezu A, Vale MM (2015) Patterns of vertebrate diversity and protection in Brazil. PLoS ONE 10: e0145064.

Joppa LN, Pfaff A (2011) Global protected area impacts. Proceedings of the Royal Society B: Biological Sciences 278: 1633-1638.

Karger DN, Conrad O, Böhner J, Kawohl T, Kreft H, Soria-Auza RW et al. (2017) Climatologies at high resolution for the Earth's land surface areas. Scientific Data 4: 170122.

Laurance WF, Lovejoy TE, Vasconcelos HL, Bruna EM, Didham RK, Stouffer PC et al. (2002) Ecosystem decay of Amazonian forest fragments: a 22-year investigation. Conservation Biology 16: 605-618.

Lemos Abreu D (2015) Área de Relevante Interesse Ecológico Seringal Nova Esperança. Acre, Brazil: Intenções \& Resultados.

Lewis SL, Edwards DP, Galbraith D (2015) Increasing human dominance of tropical forests. Science 349: 827-832.

Lui GV, Coomes DA (2016) Tropical nature reserves are losing their buffer zones, but leakage is not to blame. 147: 580-589.

MacDicken K, Jonsson Ö, Piña L, Marklund L, Maulo S, Contessa V et al. (2015) FAO Global Forest Resources Assessment (2nd edn). Italy, Rome: FAO.

Menton M, Milanez F, Souza JM, Cruz FSM (2021) The COVID-19 pandemic intensified resource conflicts and indigenous resistance in Brazil. World Development 138: 105222.

Mokany K, Raison RJ, Prokushkin AS (2006) Critical analysis of root:shoot ratios in terrestrial biomes. Global Change Biology 12: 84-96.

Nogueira EM, Yanai AM, de Vasconcelos SS, de Alencastro Graça PML, Fearnside PM (2018) Brazil's Amazonian protected areas as a bulwark against regional climate change. Regional Environmental Change 18: 573-579.

Nolte C, Agrawal A, Silvius KM, Soares-Filho BS (2013) Governance regime and location influence avoided deforestation success of protected areas in the Brazilian Amazon. Proceedings of the National Academy of Sciences of the United States of America 110: 4956-4961.

Numata I, Cochrane MA, Roberts DA, Soares JV, Souza CM, Sales MH (2010) Biomass collapse and carbon emissions from forest fragmentation in the Brazilian Amazon. Journal of Geophysical Research: Biogeosciences 115: G03027.

Numata I, Cochrane MA, Souza CM, Sales MH (2011) Carbon emissions from deforestation and forest fragmentation in the Brazilian Amazon. Environmental Research Letters 6: 044003.

Pacheco P, Mo K, Dudley N, Shapiro A, Aguilar-Amuchastegui N, Ling PY et al. (2021) Deforestation Fronts: Drivers and Responses in a Changing World. Gland, Switzerland: WWF.

Pebesma EJ, Bivand RS (2005) Classes and methods for spatial data in $R$. R News 5: 9-13.

Pfaff A, Robalino J, Lima E, Sandoval C, Herrera LD (2014) Governance, location and avoided deforestation from protected areas: greater restrictions can have lower impact, due to differences in location. World Development 55: 7-20.

Pressey RL, Visconti P, Ferraro PJ (2015) Making parks make a difference: poor alignment of policy, planning and management with protected-area impact, and ways forward. Philosophical Transactions of the Royal Society B: Biological Sciences 370: 20140280.

Redford KH (1992) The empty forest. BioScience 42: 412-422.

Rödig E, Cuntz M, Heinke J, Rammig A, Huth A (2017) Spatial heterogeneity of biomass and forest structure of the Amazon rain forest: linking remote sensing, forest modelling and field inventory. Global Ecology and Biogeography: 26: $1292-1302$. 
Saatchi SS, Harris NL, Brown S, Lefsky M, Mitchard ETA, Salas W et al. (2011) Benchmark map of forest carbon stocks in tropical regions across three continents. Proceedings of the National Academy of Sciences of the United States of America 108: 9899-9904.

Schleicher J, Peres CA, Amano T, Llactayo W, Leader-Williams N (2017) Conservation performance of different conservation governance regimes in the Peruvian Amazon. Scientific Reports 7: 11318.

Shah P, Baylis K (2015) Evaluating heterogeneous conservation effects of forest protection in Indonesia. PLoS ONE 10: e0124872.

Soares-Filho B, Moutinho P, Nepstad D, Anderson A, Rodrigues H, Garcia R et al. (2010) Role of Brazilian Amazon protected areas in climate change mitigation. Proceedings of the National Academy of Sciences of the United States of America 107: 10821-10826.

Soares-Filho B, Rajão R, Macedo M, Carneiro A, Costa W, Coe M et al. (2014) Cracking Brazil's Forest Code. Science 344: 363-364.

Thomas SC, Martin AR (2012) Carbon content of tree tissues: a synthesis. Forests 3: 332-352.
UNEP-WCMC \& IUCN (2018) Protected Area Profile for Brazil from the World Database of Protected Areas, July 2018. Cambridge, UK: UNEPWCMC and IUCN [www document]. URL www.protectedplanet.net

Veríssimo A, Rolla A, Vedoveto M, Futada S (2011) Áreas Protegidas na Amazônia Brasileira: avanços e desafios. Belém/São Paulo, Brazil: Imazon e ISA.

Watts J (2016) Dilma Rousseff impeachment: what you need to know - the Guardian briefing [www document]. URL https://www.theguardian.com/ news/2016/aug/31/dilma-rousseff-impeachment-brazil-what-you-need-to-know

Weiss DJ, Nelson A, Gibson HS, Temperley W, Peedell S, Lieber A et al (2018) A global map of travel time to cities to assess inequalities in accessibility in 2015. Nature 553: 333-336.

WWF (2015) Living Forests Report, Chapter 5: Saving Forests at Risk. Gland, Switzerland: WWF.

Zhao H, Wu R, Long Y, Hu J, Yang F, Jin T et al. (2019) Individual-level performance of nature reserves in forest protection and the effects of management level and establishment age. Biological Conservation 233: 23-30. 